\title{
THE IMPACTS OF INTERNSHIP PROGRAMME AND ITS EFFECTS ON THE PHYSIOTHERAPY PRACTICE IN NIGERIA
}

\author{
Onigbinde Ayodele Teslim \\ Department of Medical Rehabilitation, Faculty of Basic Medical Sciences, Obafemi Awolowo University, \\ Ile-Ife, Osun state, Nigeria. \\ email:ayotesonigbinde@yahoo.co.uk
}

\begin{abstract}
SUMMARY
Background: The recent introduction of one year internship training programme is one of the few steps taken to update standard and knowledge of upcoming physiotherapists in Nigeria. It is a compulsory one-year clinical training post-graduation from the university under the supervision of the clinicians. The major importance of introducing the new policy is to promote acquisition and utilization of new skills, and as well, develop skills and confidence already acquired during undergraduate days.

Objectives: The aim of this study was to assess and evaluate the new internship-training programme considering welfare package like salary and wages, accommodation, employment opportunities, acceptability and working environment. The study also evaluated the opinion of the supervisors on the impact of the new policy on the profession, government and clinical practice.

Method: Structured copies of self-administered questionnaires were distributed to forty-four interns at three accredited University Teaching Hospitals in Nigeria while 30 questionnaires were distributed to supervising physiotherapists in these hospitals. The response rate for interns was $100 \%$ while it was $60 \%$ for the supervisors. The data obtained from the designed questionnaire were analyzed by descriptive analysis.
\end{abstract}

Results: The result showed that the $52 \%$ of the interns were satisfied with the support from their senior colleagues, work load (80\%), freedom to plan and manage patients (100\%), and supervision from senior colleagues (62\%). They were grossly dissatisfied with their salaries (91\%), equipment available (79\%), pattern of conducting ward rounds (89\%), and office environment (58\%). The result also revealed that all the supervising physiotherapists (100\%) were satisfied with the skill and clinical practice of the interns. The result further showed that the programme has a positive impact in terms of clinical practice, confidence employment opportunity, productivity and government policy (66-100\%).

Conclusion: This study concluded that the internship programme has a remarkable positive impact on the profession of physiotherapy in Nigeria. However, the intern physiotherapists were not satisfied most especially with their monthly income and pattern of conducting clinical rounds.

KEY WORDS: Physiotherapy Internship Programme, Nigerian Physiotherapists.

\section{INTRODUCTION}

There is presently an influx of science students into physiotherapy programmes in Nigeria universities. All the training universities had updated their programmes into a five years degree programme. Physical therapy has continued to grow as a relatively unknown profession years back into a profession that is now the dream of intelligent science students. The education package has assumed applied sciences and clinical sciences framework (Hunt et al, 1998).

There are over 25,000-chartered physiotherapists in the United Kingdom as at 1994, and they are the largest health care profession in the hospitals after doctors and nurses (CSP, 1994) but in Nigeria, there are just 500 licensed physiotherapists although, this is not a true reflection as there are over 1000 physiotherapists currently practicing. This is grossly inadequate and cannot meet the demand of the populace (MRTB, 2005). Physiotherapists have expanded their areas of practice; hence, they are not limited to the hospital/clinical setting anymore. Their practice has extended to special schools, industries and sports centers. Physical therapy has now changed and as well developed to meet the required standard and the needs of today's population (Obajuluwa et al, 1990). There have been significant changes in the last two decades in physiotherapy education all over the world (Walid, 2003). The introduction of one-year internship programme 
in Nigeria is one of the few steps taken so far to update the standard and knowledge of graduating physiotherapists.

Internship is a compulsory one-year clinical training post-graduation from the university. The clinical training must be in an accredited hospital by the Medical Rehabilitation Therapists Registration Board (MRTB) of Nigeria. The interns are issued provisional license to practice by the Board. There are 24 accredited hospitals, which are mostly tertiary and state government hospitals. Only one private hospital was presently accredited for this programme (MRTB, 2002). Outside Nigeria, only very few countries involve their graduates in post-graduation internship.

In India, the students embark on internship for only 6 months and this within the 3 years training school period (HMS, 2006). The internship programme in United Arab Emirate is very similar to that of India (MHE, 2006). In Netherlands, the students embark on 37 weeks internship training at two different clinical sites but this is also during school holiday (European School of Physiotherapy, 2006). Clinical training could be obtained in a structured internship programme (Allison, 2002; Crosbie, 2002) and an effective administration and compliance by all the parties will entrench a considerable bureaucracy for a structured internship.

The internship programme now stands as the true litmus test to assess the quality of the graduates. It is also a way of checking and balancing the quality of the physiotherapy graduates. Similarly, it is an opportunity to improve the knowledge and clinical practice of such graduates. It equally serves as a complete booster to the image of the profession of physical therapy in Nigeria as there are only three other professions (Medicine, Dentistry and Pharmacy) with such a programme.

The welfare of the interns should be of utmost importance to the hospital managements. The interns should be provided with good welfare package like adequate income, accommodation, transportation, employment opportunities, acceptable and conducive working environment. It is known that good salary, autonomy of clinical judgment are closely related to job satisfaction (Adedoyin and Oyelese, 1997). The absence of suitable and conducive environment results in gross dissatisfaction and loss of dedication to job, and this may likely be a sign of failure. Kahn et al, (2005) categorized elements of satisfaction into the dormains: personal, interpersonal and organizational. Personal dormain is the relationship between the students and the clinical instructor while Organizational dormain is categorised as characteristics which include number of teachers, patients , educational methods, and the practical skills that the students learn.. Previous studies on satisfaction (Barnes and Crutchfield, 1997; Bronski and Cook,1994; American Physical Therapy Association, 1989, Speakman et al, 1996, Oyeyemi , 2001) only examined different status of qualified and licensed Physical Therapists but excluded the intern physical therapists.

The internship programme is more than a decade old in Nigeria and there is no known study that has evaluated the policy either in terms of satisfaction among the interns or the impact on the profession or government.

This study is therefore design to determine if there

was job satisfaction during the internship and to determine if there was an increase in the clinical skills and practice post internship. The study will also assess the acceptability of the policy and the general impact of the policy.

\section{METHODS \\ Subjects}

The subjects that participated in the study are 44 intern physiotherapists and 18 supervising physiotherapists. They were all sampled from 3 university teaching hospitals in Nigeria.

\section{Sampling technique}

A purposive sampling technique was used to sample opinions of both intern PTS and supervisors.

\section{Instrumentation}

Forty- four structured copies of selfadministered questionnaires were distributed to three accredited University Teaching hospitals in Nigeria. Also 30 questionnaires were administered to the supervising physiotherapists in theses hospitals. The responses rate was $100 \%$ for the interns in all the three centers while only 18 (60\%) of the supervising physiotherapists responded.

The questionnaire covered demography, procedure of employment, income and accommodation. That of the supervising physiotherapists covered conduct, clinical skills and other likely factors that may be used to assess the attitude of the interns. The questionnaires also assessed the impact of the internship training considering factors such as confidence level, productivity level, influence on government policy etc. Prior to the study, the questionnaire had been found to be reliable. 


\section{Experimental design}

The study is a survey design and was used to assess the satisfaction of intern PTS, while it was also used to sample opinions of supervising PTS on the attitude of the interns and the impact of the policy on the profession and government.

\section{Data Analysis}

The data was analysed using descriptive analysis (mean, standard deviation and percentages).

\section{RESULTS}

The result of this study showed that there are 24 males (54.5\%) and 20 females intern physiotherapists. The mean age of the interns are $25.3 \pm 2.6$ years while the age of the supervising physiotherapists was $32.4 \pm 3.9$ years. The mean year of clinical experience was found to be $10.4 \pm$ 0.4 months for the interns, while it was $7.8 \pm 4.6$ years for the supervisors (Table 1).

\section{Interns' Satisfaction}

The result showed that $46.7 \%$ of the interns used in this study were satisfied generally while $54.3 \%$ were dissatisfied. The result also showed that $18(41 \%)$ of the interns were satisfied (S) with their present job while 26 (59\%) are dissatisfied (D) when compared to their colleagues in other places. Also 23 (52\%) were satisfied with the support they are gaining from their senior colleagues while 21 (47\%) were dissatisfied. Similarly, $35(80 \%)$ of the interns were satisfied with the workload they are subjected to while 9 (20\%) were dissatisfied. However, $35(80 \%)$ of the interns were dissatisfied with the physiotherapy equipment available while $9(20 \%)$ were satisfied. All the interns $(100 \%)$ were satisfied with the freedom given to them plan and manage patients. 28 (64\%) were satisfied with the supervision from the senior colleague while 16 (36\%) were not satisfied. Thirty nine (89\%) were not satisfied with patterns of conducting clinical ward rounds. Also, 23 (52\%) interns were not satisfied with the furniture in their offices. Similarly, 40 interns (91\%) are dissatisfied with their monthly income (Table 2).

Furthermore, the result showed that all interns $(100 \%)$ were observing call duties in their hospitals but only $41 \%$ were observing night call duties. Similarly, only $41 \%$ were fully remunerated for call duty allowance. All the interns agreed that the internship programme should be sustained.

Table 1: Demographic data.

\begin{tabular}{clcc}
\hline Gender & & \\
\hline & Male & 24 & $54.5 \%$ \\
Mean Age & Female & 20 & $45.5 \%$ \\
& Interns & $25.3 \pm 2.6$ years \\
& Supervisors & $32.4 \pm 3.9$ years \\
Mean Clinical Experience & & \\
Interns & $10.4 \pm 0.4$ months \\
& Supervisors & $7.8 \pm 4.6$ years \\
\hline
\end{tabular}

Table 2: Job satisfaction as rated by the Interns.

\begin{tabular}{lllll}
\hline & No of IPT* & S (\%) & No of & IPT D (\%) \\
\hline Present job & 18 & 42 & 26 & 58 \\
Support from senior colleagues & 23 & 53 & 21 & 57 \\
Workload & 35 & 79 & 9 & 21 \\
Equipment Availability & 9 & 21 & 35 & 79 \\
Freedom to Plan and Manage Patients & 44 & 100 & 0 & 0 \\
Supervision from senior colleagues & 28 & 63 & 16 & 37 \\
Pattern of conduction ward rounds & 5 & 11 & 39 & 89 \\
Office furniture & 21 & 47 & 23 & 53 \\
Office environment & 19 & 2 & 25 & 58 \\
Monthly income & 4 & 9 & 40 & 91 \\
Mean \% & $46.7 \%$ & & $54.3 \%$ & \\
\hline IPT* = Intern physiotherapists & S = Satisfied. & \multirow{2}{*}{ D = Dissatisfied. } &
\end{tabular}




\section{Supervising Physiotherapists}

The mean age and years of experience of the supervising physiotherapists were $32.4 \pm 3.9$ years and $7.8 \pm 4.6$ years respectively. The result showed that 16 supervisors (89\%) of the supervising physiotherapists were satisfied with the punctuality of the interns at work. Similarly, 14 (78\%) of the supervising physiotherapists were also satisfied with the patient-therapist relationship of the interns. All the supervising physiotherapists $(100 \%)$ were satisfied with the skill and clinical practice of the interns (Table 3).

The result showed that $16(89 \%)$ of the supervising physiotherapists responded positively that the internship programme increased the awareness about the profession. Also, 14 (78\%) responded that it has positive impact on government policies in terms of increase in salary grade. Similarly, 16 (89\%) observed that the programme increased the productivity level of physiotherapists. Similarly, 12 (67\%), 16 (89\%), 18 (100\%), 18 (100\%) and $14(78 \%)$ responded positively to increase in employment, opportunity, increased confidence level, improvement in clinical practice, improvement in professional image and decrease in workload of the supervising physiotherapists respectively.(Table 4). However, 12 (67\%) of the supervisors are not aware of any code of ethics guiding the training.

Table 3: Supervisors assessment of interns' attitude.

\begin{tabular}{lcccc}
\hline & No of SPT & S (\%) & No of SPT** & D (\%) \\
\hline Conduct of interns & 14 & 78 & 4 & 22 \\
Obedience & 16 & 89 & 2 & 11 \\
Skill and clinical practice & 18 & 100 & 0 & 0 \\
Punctuality & 16 & 89 & 2 & 11 \\
Patient-therapists relationship & 14 & 78 & 4 & 22
\end{tabular}

SPT**= Supervisor physiotherapists. $\mathrm{S}=$ Satisfaction. $\mathrm{D}=$ Dissatisfaction

Table 4: Supervisors' Response to Impact of Internship Programme.

\begin{tabular}{lcc}
\hline & Positive impact (\%) & Negative impact (\%) \\
\hline Increase in awareness of the profession & $(16) 89 \%$ & (2) $11 \%$ \\
Positive influence on government policy & $(14) 78 \%$ & $(4) 22 \%$ \\
Increased productivity level & $(16) 89 \%$ & $(2) 11 \%$ \\
Awareness on Code of ethic & $(6) 33 \%$ & $(12) 67 \%$ \\
Increased in employment opportunity & $(12) 67 \%$ & $(6) 33 \%$ \\
Increased confidence level & $(16) 89 \%$ & $(2) 11 \%$ \\
Improvement in clinical practice & $(18) 100$ & $(0) 0 \%$ \\
Professional image & $(18) 100$ & $(0) 0 \%$ \\
Decreased workload of supervisors & $(14) 78 \%$ & $(4) 22 \%$ \\
\hline
\end{tabular}

\section{DISCUSSION}

The mean age of 25 years observed for the interns was too high. This may be attributed to the regular closure of schools due to crises in educational institution in Nigeria whereby their stay on campus was unnecessarily prolonged. The mean of 10 months clinical experience ( \pm 0.44 ) showed that the interns used in this study were capable of effectively assessing the internship programme because they have just two months to complete the programme. The result showed that most of the interns were not satisfied with their monthly take home as income. There is the tendency that they may not put in their best because salary has been associated with job satisfaction (Adedoyin and Oyelese, 1997; Oyeyemi, 2001). It was also observed that only $41 \%$ of the interns were fully remunerated for call duties and this is due to the fact that they observed night call duties. This area of discrepancy should be critically examined as it may affect the profession in the nearest future because each hospital is expected to observe uniform call duties. Also, all the final year students during training should be adequately informed on the internship programme. They should be included in the call duty rosters right from student days including night call duties, as this would have adequately 
prepared them for the task ahead, although, they will have to work under close supervision.

The revelation that $89 \%$ of the interns were not satisfied with the pattern of conducting clinical ward rounds is a strong factor that must be critically examined. The ward round is an opportunity to exchange clinical idea that will be beneficial to both the therapists and the patients. A clinical round also prompts acquisition and utilization of new skills, as well as the refinement and development of existing skills already acquired at the undergraduate level. Similarly, majority of the interns were dissatisfied with the equipment in their departments. The non-availability of essential therapeutic modality may affect the training of the interns.

The result further showed that all the interns were satisfied with the freedom given to them to plan and manage patients. The finding supported previous study where PTs were observed to have sufficient independence in clinical decision-making and were also given significant autonomy in their practice (Speakman et al, 1996). It has been propounded that people learn best if they are actively involved, and that it is important to give learners enough opportunities to carry out task themselves (French, 1994) with help if necessary (Atkins, 2003). It has been shown that the availability of learning opportunities, being supervised by more than one supervisor and the use of institutional methods of orientation increase satisfaction on student (Xu et al, 1995; Vahid et al, 2004). The result, which showed that $89 \%$ of the supervising therapists reported that the interns are obedient, can be attributed to the fact the difference in the mean value of age (approximately 7 years) between the interns and the supervisors was adequate enough to command respect. The years of clinical experience (8 years) put in by the supervisors was not adequate enough and this can be attributed to the brain drain syndrome where all qualified, elderly and experienced therapists are leaving the shore of Nigeria for greener pasture thereby allowing the younger ones to shoulder the responsibility of the supervision. Within the past decades, a wave of emigration by high skilled professionals has been observed from developing countries Nigeria inclusive and this is due to the prevailing economic hardship (Oyeyemi, 2001). The difference in age and clinical experience suggested that the greater proportion of the more experienced physiotherapists have emigrated overseas. The result in the study confirmed that the theory of 'brain drain' where well-educated and experienced Physiotherapists leaves Nigeria for greener pastures. This factor might have contributed to the poor manner of conducting ward rounds.

Furthermore, the result revealed that considering factors like increase in awareness of physiotherapy, productivity level, employment opportunity, clinical practice, professional image, workload, confidence level and effect of on government policy, internship programme has yielded a positive result in Nigeria. Considering these factors a range of $66 \%-100 \%$ of the supervising physiotherapists responded positively in favour of the internship programme. The $100 \%$ response of the supervisors that the internship improves the clinical practice is a strong indicator that there is every likelihood that graduates who passes though an internship training will make a better clinical input post training.

The interns are still students and students' satisfaction has been found to be associated with their later professional attitude (stith et al, 1998). Hence, if the students' satisfaction level and determinants are identified, necessary action can be taken to increase levels of satisfaction and subsequently improves the quality of education services offered to them (Levert et al, 2004).

\section{CONCLUSION}

Internship programme has actually had a positive impact on the profession of physiotherapy in Nigeria most especially on the financial income and increase in the knowledge base of physiotherapists. The entry point on the salary grade has increased post-internship. Also, knowledge acquisition has tremendously improved. However, despite the success of the internship programme observed in this study, intern physiotherapists were not satisfied most especially on their monthly income. The success of this programme is very encouraging.

\section{REFERENCES}

- Adedoyin R.A and Oyelese O. (1997) Career Decision-Indecision and job satisfaction in physical Therapy profession: A review. JNSP, Pg. 59-61.

- Allison G (2002) Sustainable gradient education and professional competency. Australian journal of physiotherapy, 48: 151-152.

- American Physical Therapy Association Recruitment and Retention of physical therapists in hospital setting, (1989), (order No. 76) 1111 Fairfax Street Alexandria, VA 2231-1488.

- Atkins (2003): Physiotherapist’s Experience of Implementing their Injection Therapy Skills.

Physiotherapy, Vol. 89, No 3 , 145-159. 
- Barnes M.R. and Crutchfield C.A (1997) Job satisfaction-dissatisfaction: A comparison of private practitioners and organizational physical therapists. Physical therapy, 5: 35-41.

- Bronski DC, Cook S (1994) The job satisfaction of allied health professionals. Journal of Allied Health, 7:281-287.

- Crosbie J, Gass E, Juu E, Morris M, Rwett D, Ruston Shepard L, Sullisan J, Vugnovia A, Webb E and Wright T (2002) Sustainable education and professional competency. Australian journal of physiotherapy, 48:5-7.

- CSP Exhibition Pamphlet (1994) In Good Hands.

- European School of Physiotherapy (2006), Amsterdam, Netherlands.

- French, S, Neville, S, Laing J. Teaching and Learning: A guide for therapists, (1994), Butterworth Heineman, Oxford.

- HMS. College of physiotherapy, Tumkur,(2006) India.

- Hunt, A, Adamson, B, Higgs J and Harris L (1998)، university education and the physiotherapy professional', physiotherapy, 84, 6, 264-273.

- Kahn R., Wolfe D., Quinn R; (2005): Organizational Stress, Studies in Role Conflict and Ambiguity. New York, NY: John Wiley \& Sons.

- Levert E.; Emine H.; Arzur D. et al, (2004) Predictors of job satisfaction among
Physiotherapists in Turkey. Journal of occupational Health; 46: 500-505.

- MHE.Ministry of Health Education, (2006) United Arab Emirate.

- MRTB, (2005). Medical Rehabilitation Therapists Bulletin.

- MRTB(2002). Medical Rehabilitation Therapists Bulletin August, Vol. 4 (No 8).

- Obajuluwa V.A, Faniran F.A, Oyeyemi A.Y (1990) The need to standardize the training of physiotherapists in Nigeria. Journal of the Nigeria Society of Physiotherapy, JNSP, ,Vol. IX No. 2, 32-35.

- Oyeyemi A.O, (2001) Job satisfaction traits of Nigeria physical therapists, physiotherapy theory and practice, $17,257-268$.

- Speakman CB, Pleasant J.M, Sutton GB The Job satisfaction of PTs. Physiotherapy Research International, (1996), 1, 247-254.

- Stith J.S., Butter Field W.H., Strube M.J., Deusinger S.S., Gillespie D.F. (1998): Personal, interpersonal and organizational influence on student satisfaction with clinical education. Physical Therapy. 78(6): 635-45.

- Vahid Ziace, Zahra Ahmadinejad, Ali Reza Morravedji (2004): An Evaluation on Medical Students' Satisfaction with Clinical Education and its Effectiveness Factors. 